\title{
PSICOLOGIA E A DESIGUALDADE SOCIAL NA EDUCAÇÃO SUPERIOR: AS ARTIMANHAS DE (RE)PRODUÇÕES SÓCIO- HISTÓRICAS
}

PSYCHOLOGY AND SOCIAL INEQUALITY IN HIGHER EDUCATION: THE TRICKS OF SOCIOHISTORICAL (RE)PRODUCTIONS

PSICOLOGÍA Y DESIGUALDAD SOCIAL EN LA EDUCACIÓN SUPERIOR: LOS TRUCOS DE LAS (RE)PRODUCCIONES SOCIO HISTÓRICAS

\section{Lucélia Maria Lima da Silva Gomes* Adélia Augusta Souto de Oliveira*}

\begin{abstract}
RESUMO
A abordagem da permanência do estudante em situação de desigualdade social na educação superior associa-se às açôes vinculadas aos programas para a redução dos índices de retenção e evasão. Essas ações se fundamentam no Programa Nacional de Assistência Estudantil e partem dos setores de assistência estudantil das instituições federais de ensino superior, que têm em sua composição profissionais da área de Psicologia. Realizou-se uma pesquisa qualitativa, com base nos pressupostos da Psicologia sócio-histórica, de caráter documental, sobre as ações desenvolvidas pela Psicologia nos contextos da assistência estudantil no Nordeste brasileiro. Para tanto, analisaram-se 23 documentos provenientes dos sites institucionais da assistência estudantil de nove instituições. Os resultados indicaram que a Psicologia na assistência estudantil é direcionada para uma atenção à saúde do estudante; prevalece uma concepção clínica da Psicologia escolar e educacional; açóes inovadoras são coletivas e perspectivam o desempenho acadêmico e desenvolvimento psicossocial nos diversos âmbitos da vivência universitária.
\end{abstract}

Palavras-chave: Psicologia escolar. Desigualdade. Assistência estudantil. Atuação professional.

\section{ABSTRACT}

The approach of low-income students' permanence in higher education is associated with actions linked to programs to reduce retention and dropout rates. These actions are based on the National Student Assistance Program and come from the student assistance sectors of the federal institutions of higher education, which have professionals in the area of Psychology. A qualitative

" Psicóloga na assistência estudantil da Universidade Federal de Alagoas e discente do Programa de Pós-graduação em Psicologia da Universidade Federal de Alagoas (UFAL).E-mail: lucelia.silva@proest.ufal.br.

** Docente do Programa de Pós-graduação em Psicologia da UFAL. E-mail: adeliasouto@ip.ufal.br. 
research was carried out based on the assumptions of documentary sociohistorical Psychology on the actions developed by Psychology in the context of student care in the Northeast of Brazil. For this, 23 documents from the institutional websites of student assistance of nine institutions were analyzed. The results indicated that Psychology in Student Assistance is directed towards student health care; a clinical conception of school and educational Psychology prevails; innovative actions are collective and focus on academic performance and psychosocial development in the various areas of university experience.

Keywords: School Psychology. Inequality. Student assistance. Professional performance.

\section{RESUMEN}

El enfoque de la permanencia del discente en una situación de desigualdad social en la educación superior se asocia a acciones vinculadas a programas para reducir las tasas de retención y deserción. Estas acciones se basan en el Programa Nacional de Asistencia Estudiantil y provienen de los sectores de asistencia estudiantil de las instituciones federales de educación superior, que cuentan con profesionales en el área de Psicología. Se realizó una investigación cualitativa basada en los supuestos de la Psicología sociohistórica documental sobre las acciones desarrolladas por la Psicología en el contexto del cuidado de los estudiantes en el Noreste de Brasil. Con este fin, fueron analizados 23 documentos de los sitios web institucionales de Asistencia estudiantil de nueve instituciones. Los resultados indicaron que la Psicología en la Asistencia al Estudiante está dirigida a la atención médica del discente; prevalece una concepción clínica de la Psicología Escolar y Educativa; las acciones innovadoras son colectivas y se centran en el rendimiento académico y el desarrollo psicosocial en las diversas áreas de la experiencia universitaria.

Palabras clave: Psicología escolar. Desigualdad. Asistencia estudiantil. Actuación profesional.

\section{INTRODUÇÃO}

permanência do estudante na educação superior associa-se "às condições de realização do curso, seja no plano institucional, seja no âmbito 1 individual/social do estudante, bem como do percurso acadêmico, em sua temporalidade (início, continuidade, término)" (Veloso \& Silva, 2013-2016, p. 97). Nessa direção, aponta-se como relevantes intervenções diversas, por meio de um conjunto de programas articulados que levem em consideração as 
particularidades de todos os envolvidos no processo de ensino-aprendizagem, visando a reduzir índices de retenção e evasão. Essas intervenções se materializam nas instituições de ensino superior (IFES) por meio dos setores de assistência estudantil, que se fundamentam no Programa Nacional de Assistência Estudantil (PNAES), e são representados nas universidades, em sua maioria, por próreitorias (Cêpeda, 2018).

A assistência estudantil no Brasil não se trata de uma ação recente nas IFES. De acordo com Kowalski (2012), existem vários acontecimentos da assistência estudantil no País que antecederam a institucionalização do Programa Nacional de Assistência Estudantil (PNAES), em 2010, e que datam do surgimento da primeira instituição de ensino superior brasileira. No entanto a ênfase na categoria permanência se dá no Brasil após a expansão do setor privado (com surgimento de cursos e instituiçóes nos anos de 1990) e do setor público (com a efetivação de políticas públicas direcionadas a expansão a partir dos anos 2000) (Veloso \& Silva, 2013-2016). Essa ênfase resultou das pesquisas de perfil discente realizadas, desde 1996, pelo Fórum Nacional de Pró-Reitores de Assuntos Estudantis (Fórum Nacional de Pró-reitores de Assuntos Comunitários e Estudantis [Fonaprace], 2019).

Até o momento, cinco pesquisas foram realizadas e amplamente divulgadas (1997, 2004, 2011, 2016, 2019) com o objetivo de apresentar a descrição do perfil médio socioeconômico e cultural do(a) discente das IFES. Além disso, buscam cumprir o papel de instrumentalizar os envolvidos na gestão das políticas de assistência estudantil por meio de diagnósticos, análises, acompanhamentos e avaliações, pela produção de indicadores que permitam aos gestores monitorar as políticas direcionadas ao ensino superior. Caracteriza-se, portanto, como uma ação inovadora e consequente.

As três primeiras pesquisas, divulgadas em 1997, 2004 e 2011, apontaram que quase metade da população estudantil das IFES pertencia às "classes [de renda] C, D e E”. A IV Pesquisa do Perfil Socioeconômico e Cultural dos Estudantes de Graduação das Instituições Federais de Ensino Superior Brasileiras, realizada em 2014, evidenciou que o ensino superior federal havia se tornado mais acessível, popular e inclusivo, com destaque para a principal descoberta: pela primeira vez, o percentual de estudantes com renda per capita de até um salário mínimo e meio atingia a maioria absoluta do universo pesquisado. $\mathrm{Na}$ última e V pesquisa, realizada em 2018, e divulgada em 2019, foi identificada a consolidação do processo de democratização das IFES brasileiras. Comprova-se, pois, as demandas, real e potencial, por assistência estudantil apresentada pelos discentes das IFES. 
Compreende-se, pois, que o público-alvo, especificamente das categorias C, $\mathrm{D}$ e E, "cuja renda média familiar mensal atingia, no máximo, $\mathrm{R} \$ 927,00$, valor contido na faixa vulnerabilidade social" (Fonaprace, 2019, p. 14), apresentam necessidades que precisam de suporte para finalização do curso.

A Região Nordeste é a segunda região que apresenta alto percentual de estudantes incluídos na faixa de renda per capita de até um salário mínimo e meio. Juntamente com a Região Norte, encontra-se abaixo da renda nominal média nacional. É importante destacar que foi também a segunda região que teve o número de universidades federais ampliado com o processo de expansão e democratização das IFES.

Nessa direção, foi lançado, em 2007, o Plano Nacional de Assistência estudantil (PNAES), sendo sancionado pelo Decreto $\mathrm{n}^{\circ}$ 7.234, em julho de 2010, transformando-se em um programa de governo. Considera o contexto de desigualdades no ensino superior e torna-se instrumento importante para o processo de democratização desse nível de ensino.

Como propostas de intervenção para redução das desigualdades, o PNAES aponta dez áreas estratégicas que poderão ser desenvolvidas pelas instituições, conforme necessidade discente. Volta-se para estudantes regularmente matriculados em cursos de graduação presencial e aponta como público prioritário das ações o estudante oriundo da rede pública de educação básica, que comprove renda familiar per capita de até um salário mínimo e meio.

Cada instituição, segundo o Decreto no 7.234 , tem autonomia para gerenciar as açôes bem como montar suas equipes, conforme as demandas existentes. Compõem essas equipes uma gama diversa de profissionais, entre estes o profissional de Psicologia que, de acordo com Matos, Santos e Dazzani (2016) não tem referenciais teórico-práticos para a atuação nesse contexto. Nessa direção, Moura e Facci (2016) afirmam que a atuação do psicólogo escolar no ensino superior está longe de apresentar consenso sobre o papel desempenhado por ser um campo ainda pouco explorado.

Ante o exposto, este artigo discute, por meio de pesquisa documental, as ações desenvolvidas pela Psicologia nos contextos de desigualdades sociais da assistência estudantil das IFES do Nordeste brasileiro (Sawaia, 2010).

\section{COMO TRILHAR EM UNIVERSO ON-LINE INSTITUCIONAL}

Trata-se de pesquisa qualitativa, de caráter documental, uma vez que centrou seus esforços na busca da compreensão da Psicologia, na assistência estudantil, apresentada pelas instituições da Região Nordeste, em seus documentos 
disponíveis on-line (relatórios de gestão institucional, documentos da assistência estudantil e informações no site da assistência estudantil com relação à Psicologia). O procedimento de busca e análise de informações contemplou as seguintes fases: exploratória, descritiva e interpretativa.

Como resultado da fase exploratória, realizada no fim do ano de 2018, foi encontrado um grande e precioso volume de 474 documentos, catalogados para futuros estudos. Por meio de leitura flutuante (Bardin, 2011) e executando a préanálise, selecionaram-se 148 documentos. $\mathrm{O}$ universo de informações evidenciou uma diversidade de denominações dos referidos documentos e evidenciou-se que nove instituições apresentam parte dos documentos em seus sites de divulgação. Assim, optou-se pela manutenção das IFES que apresentavam maior número de documentos, visto que permitiam uma compreensão ampliada das informações relacionadas à instituição. Nesse sentido, o universo da amostra foi composto por 87 documentos oriundos de nove instituições do Nordeste brasileiro.

Desse total, 23 são informações provenientes dos sites das nove instituições e subsidiam as reflexões aqui apresentadas, qual seja pontuar as ações desenvolvidas pela Psicologia e suas particularidades na assistência estudantil.

Os dados constituídos na análise documental foram analisados mediante a técnica de análise de conteúdo (Bardin, 2011). Três categorias temáticas foram identificadas, iluminando o processo em movimento (Vigotski, 2004), as quais se desenvolvem nesta reflexão. Importante ressaltar o exercício descritivo e interpretativo, realizados por meio de subsídio teórico vigotskiano. Assim descrevem-se as informações encontradas e disponíveis nos sites.

\section{POR ONDE ANDAMOS À PROCURA}

Com as decisões anteriormente descritas, os documentos analisados partiram de nove instituições localizadas em vários Estados da Região Nordeste, cinco delas com histórico de referência no cenário nacional e regional, entre as quais estão inclusas a Universidade Federal de Pernambuco (UFPE), a Universidade Federal Rural de Pernambuco (UFRPE), a Universidade Federal do Rio Grande do Norte (UFRN), a Universidade Federal de Alagoas (UFAL) e a Universidade Federal do Piauí (UFPI). O restante da amostra foi composto por intuiçôes mais recentes e que fizeram parte do processo de expansão (interiorização, estruturação e expansão, desenvolvimento regional e programas especiais) do governo federal, proposta que estava alinhada ao Plano Nacional de Educação (2001/2010), instituído pela Lei $\mathrm{n}^{\circ} 10.172 / 2001$, que priorizava o aumento do número de estudantes em todos os níveis e etapas de ensino. São elas: a 
Universidade Federal Rural do Semiárido (Ufersa), a Universidade da Integração Internacional da Lusofonia Afro-Brasileira (Unilab), a Universidade Federal do Sul da Bahia (UFSB), e a Universidade do Cariri (UFCA).

As pró-reitorias, em quatro instituições de assistência estudantil, recebem o nome de Pró-Reitoria de Assuntos Estudantis. Nas outras, aparecem nomes correlatos: Pró-Reitoria de Gestão Estudantil e Inclusão; Pró-Reitoria Estudantil; Pró-Reitoria de Assuntos Estudantis e Comunitários; Pró-Reitoria de Sustentabilidade e Integração Social; e Pró-Reitoria de Políticas Afirmativas e Estudantis.

Esses setores, respaldados no PNAES, devem planejar e desenvolver açōes que visem a, principalmente, minimizar os efeitos das desigualdades sociais e regionais, diminuir as taxas de retenção e evasão, e contribuir para a inclusão na educação superior (Decreto $n^{o} 7.234,2010$ ) por meio de profissionais de categoria e áreas diversas, entre estas a Psicologia.

De acordo com Moura e Facci (2016), o ensino superior e as políticas públicas educacionais se apresentam como espaço de atuação emergente para o psicólogo escolar e educacional. Dessa forma, nos últimos anos, observase o desenvolvimento de estudos com foco nesse nível de ensino (Bisinoto \& Marinho-Araújo, 2011; Gonçalves, Figueira, Barbosa, \& Peixoto, 2016; Ribeiro \& Guzzo, 2017; Santos, Souto, Silveira, Perrone, \& Dias, 2015; Serpa \& Santos, 2001). No entanto a assistência estudantil ainda é uma área do ensino superior emergente, pois se trata de contexto que ganhou ênfase recentemente devido à execução de políticas de democratização voltadas para o ensino superior.

Imersos nesse universo, identificamos as características e ações principais da Psicologia no contexto da assistência estudantil do Nordeste brasileiro, presentes nas informaçôes disponíveis nos sites da assistência estudantil das IFES. Para tanto, três categorias reflexivas foram elencadas: Psicologia, saúde e educação: uma Psicologia escolar clínica?; Psicologia em ação: atividades em foco; prioridade na educação superior: notas sobre o público-alvo da Psicologia.

Assim, seguem as descrições da Psicologia na assistência estudantil das IFES, sendo cada IFES denominada da seguinte maneira: $\mathrm{I}^{1}$, $\mathrm{I}^{2}$, e assim sucessivamente.

\section{PSICOLOGIA, SAÚDE E EDUCAÇÃO: UMA PSICOLOGIA ESCOLAR CLÍNICA NA EDUCAÇÃO?}

A Psicologia, na assistência estudantil, tem setor específico em oito instituições. Os resultados apontam que, em duas instituições $\left(\mathrm{I}^{2}, \mathrm{I}^{6}\right)$, denomina-se Serviço 
de Psicologia, e ganha nomes equivalentes em outras instituições, como Setor de Psicologia ( $\left.\mathrm{I}^{3}\right)$, Serviço de Apoio Psicológico $\left(\mathrm{I}^{5}\right)$, Setor de Atenção Psicossocial (Satepsi) $\left(\mathrm{I}^{7}\right)$, Setor de Atendimento Psicológico $\left(\mathrm{I}^{9}\right)$, Núcleo de Atenção à Saúde do Estudante (NASE) (I¹), Setor de Acessibilidade e Promoção da Saúde (SAPS) $\left(\mathrm{I}^{8}\right)$. A identificação do serviço pode variar entre os campi diferentes da mesma Instituição. $\mathrm{Na} \mathrm{I}^{9}$, o nome do serviço, em outros campi tem o nome de Serviço de Apoio Psicopedagógico.

Observou-se que os setores de Psicologia, na estrutura organizacional da assistência estudantil de quatro IFES, estão vinculados a uma coordenação ou área relacionada à saúde e qualidade de vida do estudante, recebendo as seguintes denominações: Coordenadoria de Atenção à Saúde do Estudante; Coordenação de Esporte e Saúde; Coordenação de Assistência à Saúde do Estudante; Coordenação de Qualidade de Vida do Estudante. Ainda que não esteja vinculada ao setor de saúde, uma IFES apontou como proposta açóes de promoção à saúde mental. Outras duas IFES, em que não se identificou vinculação a outro setor, apontaram como objetivo desenvolver ações na área da saúde, como apoiar e assistir a saúde do estudante e ações de atenção à saúde do estudante.

É importante destacar que, no último relatório da $\mathrm{V}$ Pesquisa do perfil socioeconômico dos estudantes das IFES (Fonaprace, 2019), as questôes emocionais e de saúde mental são encontradas no tópico referente à saúde e qualidade de vida dos graduandos, que se dedica à interpretação dos hábitos estudantis relacionados à alimentação, cuidados médicos e odontológicos, bem como situaçôes vividas que possam afetar a trajetória acadêmica.

Nessa direção, os achados apontam que a Psicologia está situada na área de Atenção à Saúde do PNAES, considerado, portanto, profissional da saúde, como apontado por uma das IFES: "O setor conta com profissionais de saúde que trabalham intra e interdisciplinarmente" $\left(\mathrm{I}^{8}\right)$. O processo saúde-doença foi apontado por outra IFES $\left(\mathrm{I}^{7}\right)$, ao trazer uma das atribuições do psicólogo: "Construir espaços para escuta e expressão de sentimentos, sentidos e experiências relativos aos desafios do cotidiano acadêmico e ao processo saúde-doençacuidado, atentando para suas relações com as práticas culturais".

É importante ressaltar que a atenção à saúde não se trata de objetivo das ações do Ministério de Educação (MEC), mas uma das maneiras de propiciar a redução da evasão (Bleicher \& de Oliveira, 2016). De acordo com Fonaprace (2019), os profissionais mencionados no relatório, como médicos, dentistas, psicólogos e outros, são chamados a atuar para dirimir ou intervir em situações vivenciadas pelos discentes as quais possam atrapalhar o percurso acadêmico, 
e que resultem em retenção e evasão. Para que haja enfrentamento desses dois fenômenos, os objetivos dos setores de Psicologia enfatizam os cuidados com os problemas e dificuldades apresentadas pelo discente, seja no intuito de intervir quando já instaladas ou no sentido de preveni-las.

De acordo com a I", o Serviço de Psicologia tinha como objetivo intervir "nos problemas psicossociais e psicoeducacionais que interfiram na permanência e no desempenho acadêmico". Embora a $\mathrm{I}^{9}$ aponte como objetivo desenvolver a melhoria da qualidade de vida no ambiente universitário, suas ações centramse nas dificuldades, problemas e sofrimento psicológico do estudante. A I ${ }^{6}$ aponta que é seu objetivo desenvolver ações que possibilitem "estratégias para lidar com as dificuldades pessoais, familiares, acadêmicas e profissionais". $\mathrm{Na}$ $\mathrm{I}^{2}$, a coordenação a que o setor está vinculado tem como objetivo atuar no processo ensino-aprendizagem, com a identificação de problemas e obstáculos que interfiram na integração do aluno à vida estudantil. Assim destacam: "Realizar atendimento [. . .] aos estudantes que necessitam de apoio" $\left(\mathrm{I}^{3}\right)$, "prestar assistência" ( $\left.\mathrm{I}^{1}\right)$, "podendo ser abordado qualquer questão que provoque sofrimento e/ou incomodo" $\left(\mathrm{I}^{7}\right)$. Apareceram como referência ao sujeito com dificuldade ou problema instalado.

Nessa direção, ao fazer uma analogia com a atuação da Psicologia na educação básica, Sampaio (2010, p. 102) aponta que "Esse jeito de pensar a psicologia focada em 'problemas' e 'dificuldades', transplantados para o ensino superior, poderão ser tão desastrosas quanto já o é para crianças e adolescentes". $\mathrm{Na}$ educação básica, Antunes (2008) também alerta para a atuação do psicólogo escolar como um clínico-terapeuta.

Ressalta-se ainda que, em concomitância, os documentos apresentam propostas mais ampliadas no contexto da educação, tais como apoiar no "desempenho acadêmico e o desenvolvimento psicossocial" $\left(\mathrm{I}^{9}\right)$; "possibilitar estratégias para lidar com dificuldades [. . .] acadêmicas e profissionais" $\left(\mathrm{I}^{6}\right)$; promover "melhor qualidade de vida à comunidade acadêmica" $\left(\mathrm{I}^{8}\right)$; atuar "no processo ensinoaprendizagem" $\left(\mathrm{I}^{2}\right)$; intervir "nos problemas [. . .] psicoeducacionais" $\left(\mathrm{I}^{5}\right)$; além de buscar "desenvolver habilidades acadêmicas" $\left(\mathrm{I}^{3}\right)$, o que aponta para uma interface entre saúde e educação na assistência estudantil.

Os achados sugerem que a Psicologia na assistência estudantil assume resquícios da "Psicologia Escolar Clínica" (Andaló, 1984, p. 43), em que assume "uma vinculação com a área de saúde mental, onde os problemas são equacionados em termos de saúde $\mathrm{x}$ doença, o que na escola se retraduz como problemas de ajustamento e adaptação". Estes afetariam a permanência, o que ocasiona a evasão do estudante. Nessa perspectiva, tal afirmativa pode ser ampliada e 
alcançar os apontamentos a seguir, relacionados às atividades desenvolvidas por psicólogos.

\section{PSICOLOGIA EM PRÁTICA: ATIVIDADES EM FOCO}

Pode-se afirmar que as atividades realizadas pela Psicologia na assistência estudantil são majoritariamente voltadas para atendimento psicológico individual, com espectro de variações desse tipo de atendimento no contexto educacional, os quais podem ser por meio de ações de curto prazo (plantão psicológico; acolhimento psicológico; escuta psicológica; aconselhamento psicológico; apoio psicológico; atendimento emergencial; orientação aos discentes; orientação profissional; atendimento psicopedagógico) ou de ações de médio/longo prazo (psicoterapia breve; acompanhamento psicológico; acompanhamento psicoterapêutico; atendimento psicológico clínico).

Como desdobramentos da ação de atendimento psicológico, aparecem os encaminhamentos para rede, o atendimento (orientação) ao familiar e ao docente, e as visitas domiciliares. Essas iniciativas buscam ampliar o espectro do cuidado, com a manutenção de ênfase no discente. Ressalta-se que, em cinco das instituições $\left(\mathrm{I}^{1}, \mathrm{I}^{2}, \mathrm{I}^{4}, \mathrm{I}^{8}, \mathrm{I}^{9}\right)$, apenas as ações de caráter individual são apontadas como parte das ações da Psicologia na assistência estudantil.

Destacam-se ações de atendimento individual com enfoque pontual e emergencial, como os plantões psicológicos e ações de orientação ao público universitário. O plantão psicológico esteve presente em quatro IFES, e seus derivados, como apoio psicológico e atendimento emergencial, em mais duas IFES.

Nesse sentido, de acordo com Moura e Facci (2016), o atendimento individual propicia grande procura por profissionais de Psicologia. Essa demanda, atrelada ao pequeno quantitativo de profissionais de Psicologia nas IFES, requer dos profissionais a elaboração de estratégias para atendê-la. Assim, "de modo individual, com base em uma perspectiva clínica da Psicologia Escolar e Educacional e de acordo com a demanda, ou seja, independentemente de planejamentos e objetivos" (Moura \& Facci, 2016, p. 507).

Por outro lado, destaca-se que, além das atividades de caráter individual, são divulgadas informações sobre as ações de caráter coletivo e, ou, grupal. Observaram-se atividades de grupo diversas: grupos de apoio - psicoterapêutico; psicossocial; psicoeducativo; grupos de psicoterapia; rodas de conversa; mediação de conflitos; grupo de reorientação e orientação profissional; oficinas; cursos; palestras. São práticas inovadoras nesse contexto. 
No entanto, a partir das informações identificadas expostas acima, evidenciase a predominância de formas de atuação denominadas "tradicionais", práticas que foram "associadas à dimensão psicoeducativa do contexto escolar" (Martinez, 2009, p. 171).

Para a autora, as ações tradicionais envolvem avaliação, diagnóstico, atendimento e encaminhamento de alunos com dificuldades escolares, orientação a alunos e pais, orientação profissional, orientação sexual e formação e orientação de professores, propostas que já têm histórico consolidado no País.

Observa-se, no entanto, em menor proporção, formas de atuação "emergentes", entre as quais elencamos: levantamento das necessidades e dificuldades da comunidade universitária; programas e projetos voltados para melhoria das habilidades acadêmicas e planejamento de carreiras; proposição de alternativas no que se refere às políticas e planos, que visem ao bem-estar da comunidade acadêmica; ações de promoção e prevenção em saúde (campanhas socioeducativas). Essas formas de atuação adquirem concepção ampliada do trabalho do profissional de Psicologia, que abrangem uma dimensão psicossocial, em que o contexto educacional é visto "não apenas como um lugar onde uns ensinam e outros aprendem, mas como um espaço social sui generis no qual as pessoas convivem e atuam" (Martinez, 2009, p. 172).

É importante apontar a presença, em três instituições, de iniciativas de relevante articulação do trabalho. Trata-se de ações que ocorrem em parceria com outros profissionais da universidade ou externos. Destacam-se: apoio às ações pedagógicas; a interlocução com docentes e outros setores da universidade; intercâmbio com outros órgãos da administração pública; participação na execução e acompanhamento de programas da assistência estudantil, juntamente com outras categorias e na proposição de alternativas no que se referem às políticas, planos e decisões relacionadas ao bem-estar da comunidade estudantil, e encaminhamentos dos estudantes.

Esses resultados corroboram os encontrados por Bisinoto e Marinho-Araújo (2011) e Oliveira e Silva (2018), estudos realizados, respectivamente, com profissionais de Psicologia atuantes no ensino superior do Distrito Federal e psicólogos da assistência estudantil de universidades públicas federais mineiras. No estudo de Bisinoto e Marinho-Araújo (2011), as atividades tradicionais corresponderam a $52 \%$ do total, prevalecendo, portanto, sobre as emergentes. Nos achados de Oliveira e Silva (2018), predominaram as modalidades de atendimento individual ao estudante, consideradas formas de atuação tradicionais. 
Desse modo, uma dimensão imprescindível para a reflexão reside na preocupação com os discentes. Esse âmbito se apresenta com destaque nos documentos analisados.

\section{PRIORIDADE NA EDUCAÇÃO SUPERIOR: NOTAS SOBRE O PÚBLICO-ALVO DA PSICOLOGIA}

As ações da Psicologia na assistência estudantil se voltam para o estudante em oito instituições. Uma delas $\left(\mathrm{I}^{5}\right)$ tem também a comunidade universitária (estudantes e servidores) como foco de suas intervençôes. Em outras duas, os atendimentos se voltam para familiares e docentes, no entanto como atividade pontual de orientação, extensão do atendimento ao aluno. Caracteriza-se, portanto, apenas quando necessário. Tais achados estão em acordo com os estudos já realizados (Bisinoto \& Marinho-Araújo, 2011; Moura \& Facci, 2016; Serpa \& Santos, 2001).

Vale salientar que o Decreto $n^{\circ} 7.234 / 2010$, em seu artigo $3^{\circ}$, aponta o estudante de graduação presencial como foco de suas ações, o que não foi identificado nos documentos analisados. Atualmente as IFES dispóem de estudantes de graduação (presencial e à distância) e de pós-graduação.

Além disso, de acordo com o Decreto no 7.234 (2010):

Serão atendidos no âmbito do PNAES prioritariamente estudantes oriundos da rede pública de educação básica ou com renda familiar per capita de até um salário mínimo e meio, sem prejuízo de demais requisitos fixados pelas instituições federais de ensino superior.

No texto citado, é possível identificar que a renda é a principal variável para delimitação das ações da política de assistência estudantil. É importante destacar que o percentual de estudantes pertencentes a famílias com renda mensal per capita de até 1,5 salário mínimo tenha saltado de 44,3\%, em 1996, para 66,2\%, em 2014, alcançando 70,2\%, em 2018, este o maior patamar da série histórica (Fonaprace, 2019). Isso significa dizer que mais da metade dos estudantes das IFES brasileiras se apresentam como público-alvo da assistência estudantil, se consideramos os critérios do Decreto no 7.234/2010. A Região Nordeste, por sua vez, apresenta maior número de estudantes que pertencem a famílias com renda mensal de até um salário mínimo e meio, com percentual de 78,3\% (Fonaprace, 2019).

Assim, identificou-se que apenas três instituições apresentaram prioridade das ações da Psicologia para estudantes em situação de vulnerabilidade socioeconômica $\left(\mathrm{I}^{1}, \mathrm{I}^{2}, \mathrm{I}^{4}\right)$ ou para aqueles estudantes beneficiados pelos programas da assistência estudantil. 
Ocorre que, na maioria das IFES, há destinação do recurso financeiro para áreas de moradia, alimentação e transporte (Bleicher \& Oliveira, 2016; Leite, 2015; Santos et al., 2015), que se dá pelo repasse de auxílios financeiros diversos ou por diferentes modalidades de bolsas ao estudante. $\mathrm{O}$ acesso a estes é prioritário; apenas os estudantes que comprovem renda per capita de até um salário mínimo e meio podem, a depender do quantitativo de vagas disponíveis, ser contemplado com uma bolsa ou auxílio.

De acordo com Bleicher e Oliveira (2016), outras áreas, mesmo relevantes, como a saúde, não recebem devida atenção. É nesse sentido que Leite (2015) afirma que o PNAES assumiu um perfil excessivamente específico, compensatório e assistencialista. Essa indefinição, segundo Bleicher e Oliveira (2016, p. 546), está relacionada à falta "de regulamentação específica para as ações direcionadas pelo PNAES".

Considerando o exposto, há de se questionar se a ampliação do público adotada pelos profissionais de Psicologia da assistência estudantil (sem exigência de prioridade de público-alvo, seja de graduação e, ou, que apresente baixa condição socioeconômica) está relacionada ao contingente expressivo de estudantes em situação de vulnerabilidade socioeconômica, conforme dados apresentados pelo Fonaprace (2019), mas nem sempre contemplados pelo repasse de auxílios e bolsas, ${ }^{1}$ ou se a concepção de assistência estudantil adotada pelo profissional de Psicologia contempla todos os estudantes e, ou, comunidade universitária, adotando olhar ampliado para as ações da assistência estudantil no ensino superior. Nessa direção, pesquisas futuras são necessárias para embasamento de tais reflexões.

Com base nos achados, identifica-se uma Psicologia, situada na área de atenção à saúde do estudante, demarcada por ações "tradicionais", voltadas para o estudante universitário. As IFES, em sua maioria, não realizam um recorte de prioridade de renda e, para atender à demanda de estudantes, tende a realizar atividades pontuais e emergenciais com foco nas dificuldades apresentadas pelos estudantes. Tais achados sugerem uma prática em que a Psicologia mantém uma "Psicologia Escolar Clínica” (Andaló, 1984).

\section{ALGUMAS REFLEXÕES EM PROCESSO}

Buscou-se identificar, por meio dos documentos das IFES, especificamente as informações disponíveis sobre a Psicologia, no site da assistência estudantil, como

\footnotetext{
1 Em virtude do recurso limitado destinado para a assistência estudantil das IFES e do expressivo número de estudantes nas IFES em vulnerabilidade socioeconômica, é realizado processo seletivo via editais na assistência estudantil. O quantitativo de vagas ofertadas é limitado.
} 
esta se apresenta na assistência estudantil das IFES do Nordeste brasileiro. Nessa direção, três categorias temáticas merecem atenção e reflexão: Psicologia, saúde e educação: uma psicologia escolar clínica? Psicologia em ação: atividades em foco; prioridade na educação superior: notas sobre o público-alvo da Psicologia.

Considera-se, assim, que a Psicologia na assistência estudantil é direcionada para a área de atenção à saúde, campo específico do PNAES. Os objetivos da Psicologia se direcionam para as dificuldades dos alunos, pela realização de ações majoritariamente "tradicionais", com diversidade de ações entre as instituições. Essa diversidade pode estar relacionada à autonomia apontada pelo decreto, ou também a ausência de nortes específicos, que podem ser considerados positivos ou negativos, da norma. Ao mesmo tempo, observa-se que as pesquisas realizadas pelo Fonaprace, considerado órgão de referência para esse contexto, sugerem certa influência no direcionamento dessas ações, ao apontar na estrutura do relatório os dados relacionados à Psicologia na área de atenção à saúde, com resolução das problemáticas de saúde mental, por meio de atendimento psicológico.

Considera-se que, conforme primeiro relatório da primeira pesquisa, realizada em 1994, foi apontado que

A assistência psicoterápica é oferecida por algumas universidades, embora, nesses tempos de crise, seja uma demanda efetiva. Até mesmo as universidades que já têm este tipo de serviço sentem a necessidade de ampliá-lo sem que haja condição para tal (Fonaprace, 1994, p. 39).

Considera-se ainda que, apesar da relevante presença de ações emergentes do psicólogo escolar na assistência estudantil, ainda prevalecem os resquícios de uma "Psicologia Escolar Clínica", que adota uma perspectiva clínica da Psicologia escolar e educacional.

Por fim, defende-se que, para a atuação na assistência estudantil das IFES, faz-se necessário o desenvolvimento de ações para a articulação entre as dez áreas propostas pelo PNAES. Desse modo, propiciará à comunidade acadêmica suporte ampliado frente às necessidades relacionadas à formação e enfrentamento das desigualdades no ambiente universitário. Sabemos, no entanto, que o espectro de ações do MEC privilegia a redução da evasão. Nesse sentido, as ações desenvolvidas nas IFES, pela assistência estudantil, não podem assumir perfil substitutivo dos serviços e políticas públicas de saúde, que fazem parte da rede psicossocial, a qual está inserida o sujeito. No entanto deve assumir uma postura mediadora das potencialidades vislumbrada no contexto acadêmico para que, por suas ações, articulem com as demais esferas da rede de atenção as populações, dentro e fora da instituição. Configura-se, assim, uma história 
de atuação da Psicologia, no contexto da assistência estudantil universitário, a emitir sinais iniciais de sua construção. 


\section{REFERÊNCIAS}

Andaló, C. (1984). O papel do psicólogo escolar. Psicologia: Ciência e Profissãa, 4(1), 43-46. Recuperado a partir de http://www.scielo.br/scielo.php?script=sci_ arttext\&pid=S1414-98931984000100009

Antunes, M. (2008). Psicologia escolar e educacional: história, compromissos e perspectivas. Psicologia Escolar e Educacional, 12(2), 469-475. Recuperado a partir de http://www.scielo.br/scielo.php?script=sci_ arttext\&pid=S1413-85572008000200020

Bardin, L. (2011). Análise de conteúdo. São Paulo: Edições 70.

Bisinoto, C., \& Marinho-Araújo, C. (2011). Psicologia escolar na educação superior: atuação no Distrito Federal. Psicologia em Estudo, 16(1), 111-122. Recuperado a partir de http://www.scielo.br/pdf/pe/v16n1/a13v16n1.pdf

Bleicher, T., \& Oliveira, R. C. N. (2016). Políticas de assistência estudantil em saúde nos institutos e universidades federais. Psicologia Escolar e Educacional, 20(3), 543-549. Recuperado a partir de http://www.scielo.br/scielo. php?pid=S1413-85572016000300543\&script=sci_abstract\&tlng=pt

Cepêda, V. A. (Org.). (2018). II Pesquisa nacional do perfil das instituiçôes federais do ensino superior para a assistência estudantil: um mapeamento de capacidades $e$ instrumentos: resultados da coleta 2016. São Carlos: Ideias, Intelectuais e Instituições, Fonaprace, Andifes.

Decreto $\mathrm{n}^{\text {o }}$ 7.234, de 19 de julho de 2010. (2010, 19 julho). Dispõe sobre o Programa Nacional de Assistência Estudantil - PNAES. Brasília: Portal da Legislação. Recuperado a partir de http://www.planalto.gov.br/ccivil_03/_ Ato2007-2010/2010/Decreto/D7234.htm

Fórum Nacional de Pró-reitores de Assuntos Comunitários e Estudantis. (1994). I Pesquisa do perfil socioeconômico e cultural do estudante de graduação das IFES Brasileiras - 1994. Uberlândia, Belo Horizonte: Fonaprace.

Fórum Nacional de Pró-Reitores de Assuntos Comunitários e Estudantis. (2019). V Pesquisa nacional de perfil socioeconômico e cultural dos (as) graduandos (as) das IFES - 2018. Uberlândia, Belo Horizonte: Fonaprace. Recuperado a partir de http://www.andifes.org.br/wp-content/uploads/2019/05/ V-Pesquisa-do-Perfil-Socioecono\%CC\%82 mico-dos-Estudantes-deGraduac\%CC\%A7a\%CC\%83o-das-U.pdf 
Gonçalves, A., Figueira, M., Barbosa, M., \& Peixoto, S. (2016, abril). Em novos rumos: a psicologia escolar no ensino superior. Ciências Humanas e Sociais, 3(2), 133-152. Recuperado a partir de https://periodicos.set.edu.br/index. $\mathrm{php} /$ fitshumanas/article/view/2734

Gonçalves, V. S. A. (2001). A assistência estudantil como politica social no contexto da UFPEL: concepçôes, limites e possibilidades. (Dissertação de Mestrado), Programa de Mestrado em Política Social, Universidade Católica de Pelotas, Pelotas. Recuperado a partir de http://bdtd.ibict.br/vufind/Record/ UCPe_5f713f8f1324989f2c092e09387787e0.

Kowalski, A. V. (2012). Os (des)caminhos da politica de assistência estudantil e o desafio na garantia de direitos. (Tese de Doutorado), Pontifícia Universidade Católica do Rio Grande do Sul, Porto Alegre.

Leite, J. O. (2015). As múltiplas determinaçôes do Programa Nacional de Assistência Estudantil - Pnaes nos governos Luiz Inácio Lula da Silva. (Tese de Doutorado), Programa de Pós-Graduação em Serviço Social, Universidade Federal de Pernambuco, Recife.

Marinho-Araújo, C. M. (2015). Psicologia escolar na educação superior: novos cenários de intervenção e pesquisa. In C. M. Marinho-Araújo (Org.), Psicologia escolar: novos cenários e contextos de pesquisa, prática e formação. (pp. 155-202). Campinas: Alínea.

Martinez, A. M. (2009). Psicologia escolar e educacional: compromissos com a educação brasileira. Psicologia Escolar e Educacional, 13(1), 169-177. Recuperado a partir de http://pepsic.bvsalud.org/scielo.php?script=sci_ arttext\&pid=S1413-85572009000100020

Matos, A., Santos, J., \& Dazzani, M. (2016). O psicólogo escolar na educação superior: promovendo um olhar ampliado sobre a assistência estudantil. In Dazzani, M. \& Souza, V. Psicologia escolar crítica: teoria e prática nos contextos educacionais. (pp. 115-126). Campinas: Alínea.

Moura, F. R., \& Facci, M. G. D. (2016). A atuação do psicólogo escolar no ensino superior: configurações, desafios e proposições sobre o fracasso escolar. Psicologia Escolar e Educacional, 20(3), 503-514. Recuperado a partir de http:// www.scielo.br/scielo.php?pid=S1413-85572016000300503\&script $=$ sci_ abstract\&tlng=pt

Oliveira, A. B., \& Silva, S. M. C. (2018). A Psicologia na promoção da saúde do estudante universitário. Revista Psicologia, Diversidade e Saúde, 7(3), 363-374. 
Recuperado a partir de https://www5.bahiana.edu.br/index.php/psicologia/ article/view/1913

Ribeiro, F., \& Guzzo, R. (2017). Consciência de estudantes prounistas sobre sua inserção no ensino superior. Psicologia: Ciência e Profissão, 37(2), 418431. Recuperado a partir de http://www.scielo.br/scielo.php?pid=S141498932017000200418\&script=sci_abstract\&tlng=pt

Sampaio, S. M. R. (2010). A Psicologia na educação superior: ausências e percalços. Em Aberto, 23(83), 95-105. Recuperado a partir de http://emaberto. inep.gov.br/index.php/emaberto/article/view/2253

Santos, A. S., Souto, D. C., Silveira, K. S. D., Perrone, C. M., \& Dias, A. C. G. (2015). Atuação do psicólogo escolar e educacional no ensino superior: reflexões sobre práticas. Psicologia Escolar e Educacional, 193), 515-524. Recuperado a partir de http://www.scielo.br/pdf/pee/v19n3/2175-3539-pee-19-03-00515. pdf

Sawaia, B. B. (2010). Psicologia e desigualdade social: uma reflexão sobre liberdade e transformação social. Psicologia \& Sociedade, 21(3), 364-370. Recuperado a patir de http://dx.doi.org/10.1590/S0102-71822009000300010

Serpa, M., \& Santos, A. (2001). Atuação no ensino superior: um novo campo para o psicólogo escolar. Psicologia Escolar e Educacional, 5(1), 2735. Recuperado a partir de http://pepsic.bvsalud.org/scielo.php?script=sci_ arttext\&pid=S1413-85572001000100004

Veloso, T., \& Silva, M. (2013-2016). Avaliação de programas de expansão e ingresso nas universidades federais e os reflexos na permanência do estudante. Educação em Debate, 35-38(66-71), 94-104. Recuperado a partir de http:// www.periodicosfaced.ufc.br/index.php/educacaoemdebate/article/view/74

Vigotski, L. S. (2004). Teoria e método em Psicologia. São Paulo: Martins Fontes. 